\title{
Crenças Essencialistas Sobre Policiais e Delinquentes ${ }^{1}$
}

\author{
Marcos Emanoel Pereira ${ }^{2}$ \\ Universidade Federal da Bahia \\ José Luis Álvaro Estramiana \\ Universidad Complutense de Madrid \\ Clara Vasconcelos \\ Marcus Vinicius Alves \\ Universidade Federal da Bahia
}

\begin{abstract}
RESUMO - O objetivo deste artigo foi descrever crenças esssencialistas em um experimento no paradigma do transplante de cérebro. Participantes brasileiros (101) e espanhóis (138) foram submetidos a um experimento mental de desenho 2 (país) x 2 (direção do transplante). A análise loglinear não evidenciou um claro efeito principal do país, embora tenha identificado uma interação entre o país e o transplante de cérebro. Posteriormente, as justificativas apresentadas pelos participantes foram analisadas e o que evidenciou que as pressões situacionais foram arroladas para explicar a estabilidade da conduta, enquanto as demais fontes explicativas foram adotadas predominantemente para explicar mudanças no comportamento decorrentes do transplante do cérebro. Implicações são discutidas.
\end{abstract}

Palavras-Chave: essencialismo; naturalização; entitatividade; policial; delinquente.

\section{Essentialistic Beliefs about Policemen and Criminals}

\begin{abstract}
The purpose of this article is to report the results of an experimental study about essentialistic beliefs conducted according to the brain transplant paradigm. A sample of Brazilians (101) and Spaniards (138) were submitted to a mental experiment in a 2 (Country) x 2 (direction of the brain's transplant) design. A log-linear analysis showed no clear main effects of the country, but an interaction between country and brain transfer. The justifications given by the participants were analyzed showing that contextual pressures were adopted to justify the stability of behavior while other type of explanations were mainly used to justify behavioral changes after the presumed brain transplant. The implications of these findings are discussed.
\end{abstract}

Keywords: essentialism; naturalism; entitativity; police-men; criminals.

A distinção entre o bem e o mal é uma das características mais marcantes das relações sociais empreendidas entre indivíduos e grupos humanos. Dada a sua natureza onipresente, ela constitui um importante elemento para a elaboração de estudos comparativos entre culturas distintas. O presente estudo tem por objetivo analisar, de forma comparativa, o julgamento realizado por participantes brasileiros e espanhóis a respeito de policiais e delinquentes.

A dualidade entre o bem e o mal se manifesta em vários domínios, expressando-se claramente nos mitos, nas religiões, na literatura e, mais recentemente, em produtos da indústria do entretenimento, tais como as obras cinematográficas, as séries de televisão, as histórias em quadrinhos ou as telenovelas. Denominar alguém bandido ou herói é uma operação psicológica que envolve a ativação de rótulos

1 O presente trabalho foi realizado durante estágio pós-doutoral do primeiro autor na Universidade Complutense de Madrid e na Universidade de Cambridge. $\mathrm{O}$ autor agradece à CAPES (Comissão de Aperfeiçoamento do Pessoal do Ensino Superior, sem a qual o estágio e conseqüentemente o estudo que deu origem ao presente artigo não teria sido realizado. $\mathrm{O}$ trabalho de pesquisa também recebeu suporte financeiro da FAPESB (Fundação de Amparo à Pesquisa do Estado da Bahia), nos termos do projeto 8562/2007. Apoio: CAPES/FAPESB.

2 Endereço para correspondência: Marcos Emanoel Pereira. Rua Rodrigo Argolo, 293 apt. 502, Rio Vermelho, Salvador, Bahia. Telefone: 7132407792. E-mail para contato: memanoel@gmail.com verbais. A aplicação destes rótulos é uma das características mais destacadas do processo de categorização social, pois se presume que este processo seja automático e incondicional, fugindo ao controle do agente cognitivo (Macrae \& Bodenhausen, 2000). Estes rótulos não são simplesmente palavras, nem são neutros, pois alguns acarretam mais impactos para o alvo da categorização do que outros.

Os critérios que presidem a aplicação dos rótulos verbais, no entanto, não são homogêneos. Se o rótulo for aplicado com base na crença de que a característica atribuída se relaciona com a natureza daquele que é rotulado, certamente o impacto será mais poderoso que nas situações em que o rótulo tiver sido aplicado com base no entendimento de que foram as circunstâncias da situação e os papéis sociais que fizeram com que o alvo do julgamento fosse obrigado a expressar um determinado padrão de conduta.

Ainda que muitos fatores possam levar uma pessoa a trilhar o caminho do crime, o julgamento coletivo muitas vezes tende a considerar o criminoso como alguém que se caracteriza pela presença de alguma tendência desviante de personalidade. Teorias psicossociais mais recentes sobre a categorização têm introduzido uma nova forma de circunscrever a questão do julgamento social dos criminosos. A tese da essência natural do criminoso se sustenta em uma premissa, expressa pela escola positivista italiana de direito penal, na qual se admite que os atos criminosos não decorrem de atos 
de má vontade e nem são perpetrados por uma ação volitiva do criminoso e sim por que este é o portador de uma tendência anti-social ausente nas pessoas normais. Justifica-se, desta forma, o direito de punição ao criminoso, pois apesar deste não poder vir a ser responsabilizado pela intenção de cometer o crime, ele seria potencialmente perigoso para a vida em sociedade. Em outros termos, esta tradição de pensamento sustenta a tese de que os criminosos cometem crimes pelo simples fato de eles serem naturalmente inclinados a tal, justificando-se assim a suspeita de que eles jamais deixarão de ser criminosos.

O que fundamenta a enorme aceitação de crenças a respeito da essência do criminoso? Por que apesar da atual negação veemente das teses lombrosianas a visão essencialista sobre os criminosos não é sempre colocada em dúvida? $\mathrm{O}$ essencialismo, uma teoria que procura identificar como as pessoas comuns elaboram a percepção que possuem a respeito dos grupos, sugere que os membros de um mesmo grupo, apesar das semelhanças superficiais, são vistos como compartilhando com os outros membros uma estrutura profunda que permite diferenciá-los dos membros dos demais grupos (Yzerbyt, Rocher \& Schadron, 1997). O essencialismo psicológico (Medin, 1989) se apresenta como uma alternativa às dificuldades encontradas pelas teorias clássicas da categorização, identificadas inicialmente nos trabalhos desenvolvidos dentro de uma tradição inaugurada por E. Rosch (Rosch, 1975; Rosch, Mervis, Gray, Johnson \& Boyes-Braem, 1976). Uma primeira dificuldade se relaciona com a impossibilidade de especificar toda a lista de fatores capazes de compor uma categoria psicológica. Seria possível listar todos os fatores necessários e obrigatórios capazes de permitir a inclusão de alguém na categoria criminoso? Uma segunda dificuldade advém do fato de que muitos objetos podem ser incluídos numa categoria, ainda que não possuam todos os fatores necessários e exigidos para tal. Isto ocorre porque alguns elementos são vistos como mais representativos da categoria do que outros. Por exemplo, um adolescente que compra um DVD pirata de um vendedor ambulante numa esquina é tão criminoso quanto um sequestrador? Enfim, a teoria clássica é incapaz de reconhecer que a inclusão de qualquer objeto em qualquer categoria é uma operação necessariamente ambígua. Efetivamente, pode-se afirmar que uma criança que faz downloads ilegais de música pela internet está cometendo um crime, mesmo que a definição clássica indique que ela está atendendo aos critérios que permitam defini-la como criminosa e, portanto, deve ser categorizada como tal?

Dadas as dificuldades enfrentadas pela concepção clássica da categorização foram desenvolvidas alternativas que procuraram superar estes limites (Rothbart \& Taylor, 1992). Duas grandes estruturas representacionais foram postuladas como alternativas ao modelo clássico. A primeira se refere a um sistema de codificação extremamente abstrato, dotado da capacidade de resumir e qualificar os elementos mais salientes de uma categoria. A literatura, as histórias em quadrinhos e o cinema têm criado personagens que representam de forma prototípica as várias categorias de criminosos. Personagens como os Irmãos Metralha, Odete Roitman ou Dick Vigarista representam bem estas formas representacionais abstratas.

A teoria dos protótipos foi incapaz, no entanto, de superar dificuldades acentuadas pela teoria dos exemplares, em especial o problema da variabilidade intracategórica (Sherman, 1996). O caso de uma pessoa categorizada como criminosa elucida bem esta dificuldade. Algumas modalidades de criminosos, ladrões, assassinos, traficantes de drogas, correspondem amiúde a uma visão prototípica dos membros desta categoria; outros, como os criminosos de colarinho branco ou hackers, nem tanto. A teoria da categorização mediante exemplares sugere que a categorização não é disparada em função da percepção abstrata dos membros de uma determinada categoria, mas sim que se fundamenta nas similaridades percebidas entre quem é percebido e algum exemplar específico armazenado na memória. Por exemplo, uma experiência incomum pode levar a formação de uma representação dos estereótipos de um ladrão e esta representação pode ficar armazenada na memória sob a forma de exemplar; algumas experiências com os membros desta categoria social podem favorecer a elaboração de uma representação mais abstrata dos membros da categoria social e, circunstancialmente, favorecer a substituição da representação mais concreta por uma representação prototípica dos membros da categoria social.

Talvez por terem adotado um mesmo critério como o fator decisivo para a inclusão de um determinado alvo de julgamento em uma categoria, a similaridade, nenhuma das duas teorias foi capaz de apreender algumas questões fundamentais do processo de categorização. Uma destas questões se refere à aceitação da similaridade como um critério a ser adotado para estabelecer uma relação de correspondência entre quem é percebido e um protótipo ou exemplar. Estas teorias evidenciam claramente os seus limites ao não conseguirem esclarecer o que determina que alguns fatores, e não outros, sejam privilegiados durante a operação de categorização e se ressentem de dificuldades decorrentes da adesão à tese de que a categorização é possível quando se obtém um ajuste fundamentado na similaridade entre os alvos de julgamento e os protótipos da categoria e os exemplares armazenados na memória.

Esta tese desconsidera que as semelhanças superficiais e observáveis entre os objetos são enganadoras e, como tais, podem levar a uma categorização inapropriada (Medin, Goldstone \& Gentner, 1993), sendo preferível admitir que a similaridade tanto pode ser uma consequente como um antecedente da categorização. Assim, dois objetos sociais podem ser considerados similares apesar das suas diferenças na aparência. Esta idéia se sustenta no argumento de que duas coisas podem ser consideradas similares, apesar das suas diferenças superficiais, se o percebedor acolher uma teoria que justifique o tratamento dos objetos diferentes entre si como membros de uma mesma categoria (Medin \& Shoben, 1988). Esta nova formulação sugere que a categorização social se manifesta prioritariamente mediante a organização dos entes percebidos e das categorias sociais em torno de uma estrutura explicativa, usualmente uma teoria implícita.

Desta forma, qualquer formulação mais abrangente da teoria da categorização social deve incluir tanto o impacto da similaridade percebida, quanto o das teorias implícitas do percebedor; tanto os fatores superficiais, quanto os elementos mais profundos da categorização. Esta diferenciação é fundamental para a teoria essencialista, uma vez que esta se sustenta no entendimento de que as pessoas agem como se 
as coisas possuíssem essências, ou seja, como elas fossem constituídas por estruturas profundas e imutáveis que as fazem ser o que são.

Os trabalhos desenvolvidos por Haslam (1998) evidenciam, com base numa cuidadosa análise da dimensão ontológica dos grupos humanos, que o essencialismo deve ser concebido como um conceito heterogêneo e bidimensional, uma vez que incorpora tanto uma dimensão que se refere ao processo de naturalização de categorias sociais, como as de idade, raça ou gênero, quanto a percepção reificada de outras categorias sociais, como as políticas, as econômicas, as religiosas ou as sociais. Deste modo, a articulação destas duas dimensões, uma naturalizadora, que propicia a crença de que as condutas dos indivíduos, por sofrerem a influência da sua própria natureza, seriam estáveis e imutáveis, e outra, a entitativa, que permite perceber e identificar a organização interna dos entes que constituem os grupos e as categorias sociais, fundamenta a teoria essencialista da categorização.

Esta dupla dimensão da essencialização termina por favorecer o desenvolvimento da crença de que os membros de uma categoria, ainda que venham a modificar os seus elementos de superfície, como os trajes, os gestos, as posturas ou penteados, jamais deixarão de ser percebidos como depositários das características próprias da categoria a qual pertencem. Desta forma, a aplicação do raciocínio essencialista faz que uma pessoa pobre, por mais que consiga ascender economicamente, provavelmente continuará a ser percebida e tratada como pobre. Um raciocínio semelhante pode ser aplicado aos criminosos, pois estes, ainda que tenham cumprido a pena e "pago a dívida para com a sociedade", são julgados como irrecuperáveis e potencialmente suscetíveis a um retorno às trilhas da criminalidade.

A adoção deste tipo de raciocínio produz um impacto bastante considerável nas relações sociais ordinárias, contribuindo para a expressão e manifestação de fenômenos como a acentuação perceptual das diferenças intergrupais, a discriminação, a tendência à desumanização de membros de outros grupos e a justificação das desigualdades sociais (Haslam, Bain, Douge, Lee \& Bastian, 2005; Keller, 2005; Picket, 2001). A aplicação do raciocínio essencialista tanto pode ser interpretada como um tipo de atalho mental, quanto pode ser considerado algo mais complexo que um simples viés heurístico, pois a essencialização, ao permitir que sejam criadas ou simplesmente ratificadas teorias sobre as diferenças entre os grupos humanos, desempenha um papel fundamental na manutenção das estruturas econômicas, sociais e políticas, assim como na justificação e racionalização das hierarquias sociais.

Um dos primeiros trabalhos a enfrentar sistematicamente esta discussão foi realizado por Mahaligam, onde são apresentadas evidências a respeito do impacto da essencialização nas teorias folk no sistema de castas na Índia (Mahalingam, 2003) e são oferecidos indicadores de que os participantes adotaram teorias explicativas distintas para justificar a estabilidade e a mudança social. Uma destas teorias assentava-se no entendimento de que as diferenças entre os grupos eram genéticas e fisiológicas, tendo sido adotada predominante pelos brâmanes, enquanto uma segunda, apoiada pelos dahlits (antigos intocáveis), fundamentava-se na crença de que as diferenças entre os grupos decorriam de fatores como a socialização, os papéis e as normas sociais. Tais resultados oferecem suporte para o entendimento de que os argumentos essencialistas podem assumir formulações diferentes e podem cumprir distintos papéis na dinâmica das relações intergrupais, embora tenha sido identificada uma tendência para a adoção do raciocínio essencialista fundamentado na naturalização entre os membros dos grupos sociais dominantes, enquanto o raciocínio essencialista de fundamentação entitativa tende a ser usualmente adotado pelos grupos sociais que se encontram em condições desfavoráveis.

\section{Explicações folk do comportamento humano: os criminosos como exemplo}

Os teóricos da atribuição da causalidade têm acentuado, há algumas décadas, que os seres humanos procuram dotar o mundo em que vivem de sentido e, para tal, desenvolvem teorias explicativas a respeito dos eventos que ocorrem com eles mesmos, com os outros e com os objetos presentes no mundo físico. Embora Fritz Heider tenha sido o primeiro a sistematizar estas teorias explicativas em termos de atribuições de causas pessoais e impessoais (Heider, 1970), posteriormente, e provavelmente devido ao impacto da teoria da inferência correspondente, estas causas foram localizadas na pessoa ou no ambiente (Jones \& Davis, 1965).

As causas e razões de um crime de colarinho branco, como, por exemplo, a venda de segredos industriais para uma empresa concorrente, seriam as mesmas que levariam um serial killer a cometer inúmeros assassinatos com requintes de crueldade? Provavelmente, não. Quando as pessoas tomam conhecimento de eventos desta natureza, refletem sobre o assunto e elaboram teorias explicativas sobre as causas, as motivações ocultas ou mesmo as intenções deliberadas dos criminosos. Uma vez que um crime ganha notoriedade, criminólogos, psicólogos, advogados, juristas e sociólogos são convidados pelos meios de comunicação para irem a público explicar as razões e os motivos do ato criminoso. Tais explicações, usualmente, são utilizadas pelas pessoas sem formação especializada nas suas tentativas de oferecer sentido ao mundo em que vivem.

Ainda que seja possível fazer referências genéricas sobre as causas que levam uma pessoa a se tornar um criminoso, é bem provável que estas concepções estereotipadas sejam por demais abstratas para exercer um papel importante na economia psíquica. As representações estereotipadas devem oscilar, portanto, entre uma representação mais abstrata e prototípica do criminoso e as representações armazenadas na memória dos vários exemplares de criminosos e de crimes que ganharam notoriedade.

\section{Objetivos e hipóteses}

Fundamentado na teoria essencialista da categorização e consubstanciado no paradigma do transplante de cérebro, este estudo contempla dois objetivos: a) avaliar o impacto do país de origem e da direção do transplante de cérebro no julgamento da conduta social de policiais e criminosos; e b) analisar, segundo o modelo das explicações folk das condutas 
sociais, as justificativas apresentadas pelos participantes para as suas respostas.

A primeira hipótese assinala que, em função das diferenças existentes entre os dois países no concernente ao desenvolvimento econômico e social, às taxas de criminalidade e à veiculação de notícias pelos meios de comunicação sobre a violência de maneira geral, esperar-se-ia alguma diferença no grau de essencialização entre os participantes espanhóis e brasileiros. A segunda hipótese submetida à prova se refere à condição de hegemonia das categorias sociais e postula diferenças de julgamento nas circunstâncias em que o cérebro é transplantado de um policial para um delinquente (condição hegemônica) ou na direção inversa (condição não-hegemônica). A terceira hipótese a orientar o presente trabalho sugere que os participantes iriam manifestar diferenças em relação ao modelo explicativo adotado para a elaboração das justificativas para as respostas, sendo esperado, em função da natureza da tarefa experimental, um predomínio de teorias que se refiram às causas internas como critério fundamental para a estabilidade dos padrões de comportamento que se segue a um hipotético transplante de cérebros entre policiais e delinquentes.

\section{Método}

\section{Participantes}

Os dados da pesquisa foram coletados em instituições de ensino superior localizadas em dois países, Brasil e Espanha. Os dados obtidos na Espanha foram coletados na Universidade Complutense de Madrid e se referem a 138 estudantes, enquanto no caso brasileiro a amostra contou com 101 participantes, 66 da Universidade Federal da Bahia e 35 da Universidade Presidente Antonio Carlos, da cidade de Barbacena, Minas Gerais.

\section{Procedimentos}

Este estudo foi planejado de acordo com os protocolos experimentais adotados por Mahalingham (2003). O paradigma do transplante de cérebro foi usado originalmente em estudos conduzidos na área da psicologia do desenvolvimento, com a finalidade de investigar as propriedades inerentes à identidade pessoal e a sua estabilidade (Johnson, 1990; Gelman, 2004; Gottfried, Gelman \& Schultz, 1999), tendo sido considerado um recurso confiável para o estudo da identidade social (Mahalingan \& Rodrigues, 2003). No presente caso, os participantes foram alocados aleatoriamente em dois grupos e leram pequenas histórias sobre um personagem hipotético que recebe um transplante de cérebro de um indivíduo que pertence a uma categoria simétrica e oposta à qual pertence. $\mathrm{O}$ enunciado de uma destas histórias pode ser identificado no exemplo abaixo, no qual se apresenta a versão na qual o cérebro de um delinquente é transplantado para um policial (categoria não-hegemônia para categoria hegemônica).

\author{
"Jonas é um delinquente e Armando um policial. Alguém pega \\ o cérebro de Jonas e coloca na cabeça de Armando. Após o \\ transplante do cérebro, você acha que Armando agirá como um: \\ a) delinquente \\ b) policial",
}

Foram elaborados dois tipos de histórias, sendo uma versão relativa ao transplante de cérebros de membros da categoria hegemônica policial para a categoria não-hegemônica delinquente e a outra relativa ao transplante do cérebro da categoria delinquente para a categoria policial. Cada participante avaliou a história relativa exclusivamente a uma das duas versões da categoria entitativa policial-criminoso, ou seja, do transplante do cérebro de policial para criminoso ou do criminoso para policial

O procedimento de coleta de dados foi inteiramente conduzido mediante o uso de um protocolo computadorizado que permitiu a padronização da apresentação das instruções, aleatorização da ordem de apresentação dos itens, a reprodução das respostas aos itens e a solicitação das justificativas para as respostas, além de mensurar as respostas, oferecer ao participante um feedback sobre as respostas e gerar a base de dados. O aplicativo computacional utilizado na pesquisa foi criado com o sistema de autoria Toolbook Instructor, versão 5.01, especialmente para a investigação. $\mathrm{O}$ instrumento, originalmente criado em língua portuguesa, foi traduzido e adaptado para o espanhol por um falante bilíngue espanhol nativo.

\section{Desenho experimental}

O foco de análise do presente artigo se direciona para a condução de comparações entre o padrão de resposta de participantes brasileiros e espanhóis, quando da avaliação de um hipotético transplante de cérebro dos membros de uma categoria social entitativa dominante (policiais) para uma categoria entitativa não-dominante (criminosos) ou o transplante numa direção inversa.

\section{Resultados}

Para avaliar os efeitos conjuntos do país e da direção do transplante de cérebro nas respostas sobre estabilidade ou mudança dos comportamentos após o transplante de cérebro entre policiais e delinquentes foi conduzida uma análise loglinear, que produziu um modelo com um bom ajuste ( $\mathrm{li}$ kelihood ratio $\left.\mathrm{x}_{(4)}^{2}=0,973, \mathrm{p}=, 914\right)$, no qual se identificou apenas uma interação entre o país e o padrão de resposta. A inspeção dos coeficientes de proporcionalidade, conforme se observa na Tabela 1, aparentemente acena para uma menor tendência à essencialização entre os participantes espanhóis (0,29 para a direção do transplante policial/criminoso e 0,33 na direção inversa) quando comparada com os participantes brasileiros $(0,55$ e 0,56 , respectivamente).

As diferenças entre os dois países, no entanto, se tornam evidentes quando se analisa, mediante a inspeção das diferenças entre os valores obtidos e os esperados finais encontrados na Tabela 1, o efeito da interação entre o país e o padrão das 
Tabela 1. Frequências esperadas e obtidas, ORs (coeficientes de proporcionalidade) e ORs logarítmicos dos padrões de respostas de estabilidade e mudança entre participantes brasileiros e espanhóis

\begin{tabular}{|c|c|c|c|c|c|c|c|c|}
\hline \multirow{3}{*}{$\begin{array}{l}\text { País } \\
\text { Condição } \\
\text { Conduta }\end{array}$} & \multicolumn{4}{|c|}{ Espanha } & \multicolumn{4}{|c|}{ Brasil } \\
\hline & \multicolumn{2}{|c|}{$\begin{array}{c}\text { Policial } \\
\text { Delinquente }\end{array}$} & \multicolumn{2}{|c|}{$\begin{array}{l}\text { Delinquente } \\
\text { Policial }\end{array}$} & \multicolumn{2}{|c|}{$\begin{array}{c}\text { Policial } \\
\text { Delinquente }\end{array}$} & \multicolumn{2}{|c|}{$\begin{array}{l}\text { Delinquente } \\
\text { Policial }\end{array}$} \\
\hline & Est* & Mud** & Est & Mud & Est & Mud & Est & Mud \\
\hline Porcentagem & 7,0 & 24,4 & 6,6 & 20,2 & 7,4 & 13,6 & 7,4 & 13,2 \\
\hline \multicolumn{9}{|l|}{ Frequências } \\
\hline Obtida & 17 & 59 & 16 & 49 & 18 & 33 & 18 & 32 \\
\hline Esperada final & 16,5 & 54,0 & 16,5 & 54,0 & 18,0 & 32,5 & 18,0 & 32,5 \\
\hline Esperada independente & 17,5 & 59,5 & 16,5 & 49,5 & 18,5 & 33,5 & 18,5 & 32,5 \\
\hline OR P x C x R & \multicolumn{2}{|c|}{,29 } & \multicolumn{2}{|c|}{,33 } & \multicolumn{2}{|c|}{,55 } & \multicolumn{2}{|c|}{,56 } \\
\hline OR $\log \mathrm{P} \times \mathrm{C} \times \mathrm{R}$ & \multicolumn{2}{|c|}{,- 54} & \multicolumn{2}{|c|}{,- 49} & \multicolumn{2}{|c|}{,- 26} & \multicolumn{2}{|c|}{,- 25} \\
\hline
\end{tabular}

* Est se refere à estabilidade da conduta após o hipotético transplante de cérebro;

** Mud se refere à mudança na conduta após o hipotético transplantede cérebro.

respostas. Conforme se observa na análise das colunas relativas à mudança na conduta, as únicas condições nas quais foram observados valores residuais dignos de nota foram as avaliações dos participantes espanhóis quando o delinquente recebeu o cérebro de um policial, onde o valor obtido foi mais alto do que o esperado, e na condição inversa, na qual um policial recebe o cérebro de um delinquente, na qual o valor obtido foi menor do que o esperado. Isto indica que para os espanhóis, se o receptor do cérebro transplantado for um delinquente, ele terá mais chance de mudar o seu padrão de conduta, enquanto no caso oposto, o transplante do cérebro de um delinquente para um policial proporcionará uma chance menor de mudança no padrão de conduta.

Em suma, para os participantes espanhóis o cérebro de um policial pode modificar o padrão de conduta de um delinquente, mas o inverso não é verdadeiro. Por outro lado, o padrão de resposta dos participantes brasileiros não indicou qualquer diferença entre os valores esperados e obtidos nas respostas relacionadas com a direção do transplante do cérebro.

Os resultados discutidos anteriormente indicam uma corroboração da primeira hipótese de que seriam observadas diferenças no grau de essencialização entre participantes brasileiros quando comparados com os espanhóis, bem como oferecem suporte parcial à segunda hipótese de que as consequências de um suposto transplante de cérebro dependem da hegemonia da categoria social, o que se demonstrou exclusivamente entre os participantes espanhóis.

Os resultados, no entanto, adquirem novas cores se forem consideradas as justificativas apresentadas pelos participantes. A codificação destas justificativas foi conduzida de acordo com o modelo das explicações das condutas sociais proposto por Malle (1999; 2006) e modificado por Brewer, Hong e Li (2005), no qual são diferenciadas quatro modalidades básicas de teorias implícitas adotadas pelas pessoas quando procuram explicar as suas próprias ações, assim como as das outras pessoas. As fontes de explicação da experiência ordinária contemplam as causas internas, a história causal, as pressões situacionais e as razões. A frequência de atribuição de justificativas relacionadas a cada uma destas fontes pode ser identificada na Tabela 2.

A análise das frequências e percentagens deixa claro que as explicações mediante o apelo às pressões situacionais diferem de forma nítida das demais explicações. Apesar de corresponder a apenas $16,4 \%$ do total de explicações, esta teoria explicativa foi adotada, predominantemente, como justificativa para as respostas que aderem ao entendimento de

Tabela 2. Frequências das justificativas apresentadas sobre as condutas de policiais e delinquentes, classificadas de acordo com o nível de explicação

\begin{tabular}{|c|c|c|c|c|c|c|}
\hline \multirow{2}{*}{ Tipo de explicação } & \multicolumn{2}{|c|}{ Mudança } & \multicolumn{2}{|c|}{ Estabilidade } & \multicolumn{2}{|c|}{ Total } \\
\hline & $\mathrm{F}$ & $\%$ & $\mathrm{~F}$ & $\%$ & $\mathrm{~F}$ & $\%$ \\
\hline \multicolumn{7}{|l|}{ Causas internas } \\
\hline $\begin{array}{l}\text { Genes, hormônios, cérebro, corpo, traços e processos } \\
\text { psicológicos, essências, self }\end{array}$ & 10 & 8,2 & 111 & 91,8 & 121 & 60,2 \\
\hline \multicolumn{7}{|l|}{ História causal } \\
\hline Crenças, valores, atitudes, aparência comum & 5 & 13,9 & 31 & 86,1 & 36 & 17,9 \\
\hline \multicolumn{7}{|l|}{ Pressões situacionais } \\
\hline $\begin{array}{l}\text { Status, papéis, dinâmica grupal e coletiva, ambiente social } \\
\text { Razões }\end{array}$ & 27 & 81,8 & 6 & 18,2 & 33 & 16,4 \\
\hline Motivos e intenções & 3 & 27,2 & 8 & 72,8 & 11 & 5,5 \\
\hline Totais & 45 & 22,4 & 156 & 77,6 & 201 & 100,0 \\
\hline
\end{tabular}


que haveria uma estabilidade na conduta após o transplante do cérebro. No caso específico da categoria policial/delinquente, o valor do coeficiente de proporcionalidade $(4,5$ ou seja, 27/6) expressa uma forte tendência de utilização desta fonte para a elaboração de explicações sobre a estabilidade do comportamento. Tal resultado demonstra a importância dos papéis, do status, do ambiente social e da dinâmica individual e coletiva no processo de essencialização da categoria entitativa policial/criminoso. Tal fato pode sugerir a importância que a ocupação em si, tanto do policial, quanto do criminoso, tem na definição dos estereótipos veiculados a estes grupos e sugere, ademais, um maior poder das pressões externas sobre a avaliação da estabilidade das condutas.

Qual a natureza destas pressões situacionais, quais as justificativas apresentadas pelos participantes para adotá-las e em que circunstâncias elas são adotadas para justificar as respostas? Uma destas fontes de explicação possui um caráter difuso e se refere a uma influência mais ampla do ambiente ou entorno social ("también depende del entorno, pero supongo que aunque no lo sea desde el principio acabará volviendo a serlo", participante 4, estabilidade, Espanha). Esta forma pode se apresentar de uma maneira menos vaga, quando as referências são feitas ao meio social ("es tu forma de vivir, estás condicionado al medio en el que te ha tocado desarrollarte", participante 123, mudança, Espanha; "o meio em que o cidadão nasce ou vive influencia no seu caráter e não o funcionamento do cérebro", participante 144, estabilidade, Brasil; "o meio social em que Armando está inserido continuará o mesmo, ele continuará trabalhando como policial", participante 214, estabilidade, Brasil).

A suposição adotada nestas explicações tende a destituir a importância do cérebro e de outras fontes de explicação mais naturalizadas e acentuar o impacto de um ente supraindividual, cujo impacto se manifestaria de forma homogênea em todos aqueles que vivem sob a sua influência. Neste sentido, a explicação guardaria uma certa semelhança com o conceito sociológico de fato social ou mesmo com a noção de representações coletivas. Um dos participantes se referiu a este ente fazendo alusão ao conceito de sociedade ("o cérebro de um policial não é o suficiente para mudar a delinquência de alguém, já que esta é fruto da sociedade e educação", participante 151, estabilidade, Brasil), enquanto outro se referiu à realidade ("por que eles vivem realidade de vidas diferentes", participante 191, mudança, Brasil).

Uma forma menos abstrata de fazer referência a este ente que pairaria sobre os indivíduos se manifesta pela aceitação de que a vida social moderna demanda um serie de acordos sociais que imporia o que poderia ser chamado de circunstâncias da vida ("la circunstancias que han llevado a Jonas a desarrollar su conducta no son de corte biológico ni se sitúan en ningún hemisferio de su cerebro", participante 5, estabilidade, Espanha; "Ele era delinquente por falta de outro modo de sobreviver, agora ele tem um emprego", participante 190, mudança, Brasil).

Os demais padrões de justificativa foram utilizados com uma frequência muito mais acentuada para explicar as mudanças no padrão de conduta. Neste caso, as respostas relativas às causas internas incorporaram mais da metade da quantidade de justificativas. Isto é perfeitamente compreensível, pois a natureza da tarefa experimental favorece o uso de explicações mediante o apelo ao cérebro. As justificativas fundamentadas em causas internas foram adotadas prioritariamente para explicar as mudanças no comportamento $(91,8 \%)$, o que resulta num coeficiente de proporcionalidade de 0,09 (10/111), que indica um reduzido impacto do pensamento essencialista. Este resultado contradiz a terceira hipótese na qual se postulava que as explicações fundamentadas em causas internas corresponderiam a um maior grau de essencialização.

O resultado, ademais, indica que os participantes que aludem a este tipo de explicação concordam com o ponto de vista de que apenas uma alteração na natureza biológica do indivíduo pode gerar mudanças comportamentais. Esta suposição é confirmada mediante a evidência de que a principal fonte interna de explicação foi compreensivelmente o cérebro, fator adotado de forma sistemática para aludir às mudanças esperadas no comportamento após o transplante ("porque en el cerebro nuevo de Jonas los recuerdos y experiencias son los de un policía", participante 13, mudança, Espanha; "Armando agora estará sujeito a pensar como em policial já que seu cérebro, coordenador de suas idéias, pensa como um policial, seu comportamento provavelmente irá mudar, já que suas idéias serão outras", participante 157, mudança, Brasil) ou mesmo a estabilidade da conduta ("en el cerebro están los impulsos, las emociones...se comportará según el cerebro que tenga", participante 69, estabilidade, Espanha; "los conocimientos acerca del oficio y los razonamientos acerca de la conducta están relacionados con el cerebro", participante 92, estabilidade, Espanha).

O cérebro, no entanto, não foi o único critério fundamentado na biologia adotado para a justificação das respostas. Neste caso, foram feitas alusões a fatores como a genética e a biologia ("la conducta antisocial y agresiva tiene base genética y fisiológica", participante 51, estabilidade, Espanha; "aunque algunas conductas violentas pueden ser debidas a anomalías cromosómicas, supondremos que Jonas tiene un cuerpo normal y un cariotipo normal. El sistema endocrino de Jonas influirá también en él', participante 104, mudança, España; "seu genótipo ainda é de policial", participante 221, estabilidade, Brasil). Ainda que as teorias implícitas possam se nutrir de versões simplificadas das teorias científicas, como os anteriormente referidos conceitos de anomalias cromossômicas ou cariótipos, isto nem sempre é verdadeiro, a se depreender da adoção de explicações fundamentadas em conceitos cientificamente controvertidos, como os de instinto ("por los instintos y la forma de vida llevada hasta ese momento", participante 32, estabilidade, Espanha; "o instinto criminoso continuará na mente do cérebro transplantado", participante 186, mudança, Brasil), ou mesmo em noções absolutamente imprecisas como as de sangue (" $\mathrm{si}$ no tiene sangre de policía no lo será nunca", participante 8, estabilidade, Espanha).

Em que pese a influência da adoção de justificativas centradas na existência de causas naturalizáveis como fonte explicação internas para as mudanças nas condutas, podem ser aventadas outras modalidades de explanação que não a naturalização pela via biológica. Uma alternativa frequentemente adotada pelos participantes como justificativa para as respostas se perfila com as teorias e com os conceitos oriundos da tradição da pesquisa em psicologia e se refere a 
fatores como a personalidade ("porque esse fator está associado também a personalidade da pessoa, se for um policial com certeza será também delinquente", participante 185 , mudança, Brasil; "ele herdará sua má indole", participante 207, mudança, Brasil) ou a mentalidade ("a no ser que la agresividad venga impuesta por alguna anomalía hormonal, la conducta delictiva será propia de la mentalidad del delincuente", participante 89, mudança, Espanha). Outros participantes foram absolutamente explícitos ao se referirem a teorias claramente essencializadoras, como o caso de um participante brasileiro que justificou a sua resposta mediante a afirmação que "uma vez delinquente, sempre delinquente" (participante 211, estabilidade, Brasil).

As explicações para a estabilidade e mudança nas condutas de policiais ou criminosos podem assumir uma terceira modalidade explicativa, além das causas internas ou das pressões situacionais. Uma destas fontes de explicação se refere aos fatores relacionados com as circunstâncias presentes na história causal do indivíduo que oferecem os meios e as condições que o habilita a expressar as suas condutas em determinadas direções. Uma parcela das justificativas, cerca de $17,9 \%$, considera a história causal como fonte de explicação dos comportamentos, o que representa um coeficiente de proporcionalidade de $0,16(5 / 31)$.

Uma vez mais, este tipo de explicação foi adotado para justificar mudanças no padrão de condutas da categoria. Uma alternativa compatível com esta modalidade de explicação se refere aos hábitos. Um participante, por exemplo, expressa uma crença que reflete bem quão difícil é romper com hábitos firmemente estabelecidos ("si Jonas ha sido delincuente toda su vida, aunque le transplanten el cerebro de un policía, su hábito será delinquir", participante 7, estabilidade, Espanha). Os hábitos, embora assimilados pelos indivíduos, se formam e são reforçados pela presença de determinados costumes ou práticas de aprendizagem adotadas na sociedade, sendo possível identificar, portanto, uma outra fonte de explicação fundamentada na história causal, os costumes ("determinado por una costumbre", participante 113, estabilidade, Espanha; "si está acostumbrado a delinquir no se dará cuenta de que no lo necesita", participante 137, cambio, Espanha). Hábitos, costumes, rotinas, tradições culturais são elementos, por definição, aprendidos ao longo de uma história de vida. Muitas explicações se fundamentam, portanto, na noção de aprendizagem ("Armando volverá a aprender y a comportarse de la misma forma que antes", participante 81, estabilidade, Espanha; "porque las conductas que permanecen son las aprendidas por el cerebro del policía", participante 55, mudança, Espanha; "o modo de agir depende da absorção de caracteristicas ao longo da vida", participante 145 , estabilidade, Brasil).

Estes elementos aprendidos ao longo da trajetória de socialização são percebidos como determinantes na expressão das condutas de policiais e criminosos e favorecem o surgimento de explicações elaboradas em torno dos conceitos psicossociais de crenças e valores ("a postura adotada não tem a ver com o físico e sim com a convicção estabelecida", participante 163, mudança, Brasil; "ele vai agir como tal, porque agora ele possui valores novos", participante 195, mudança, Brasil.) Outra formulação compatível com a história causal se refere à dimensão da experiência, inter- pretada como um elemento causal tão ou mais poderoso que os determinantes cerebrais ou biológicos ("porque como ya he dicho, la conducta de un hombre también se basa en su experiencia, no sólo en la parte neuronal", participante 77 , estabilidade, Espanha; "la experiencia le habrá hecho ser delincuente y esto marcará su cerebro", participante 140, mudança, Espanha).

Dada a natureza da tarefa experimental, esperava-se um número pouco significativo de explicações sustentadas em suposições sobre as intenções deliberadas ou mesmo motivos subjacentes às ações de criminosos e delinquentes. Isto, de fato, ocorreu, pois apenas 11 justificativas, cerca de 5,5\% das respostas, fizeram alusão a esta fonte de explicação. Uma vez que o valor do coeficiente de proporcionalidade atingiu o valor $0,37(3 / 8)$, pode-se inferir que as intenções e os motivos foram adotados predominantemente como fontes de explicação para as mudanças na conduta que se seguiram ao presumido transplante de cérebro. Dentre as explicações aventadas, destaca-se aquelas centradas na noção de vontade ("acho que foi uma questão de escolha ele ser policial e essa convicção permanece", participante 225, estabilidade, Brasil).

\section{Discussão}

Nos últimos anos, as teorias psicossociais sobre a categorização têm acentuado a importância do processo de essencialização, seja por que este oferece alternativas explicativas que respondem bem aos problemas enfrentados pelas teorias clássicas dos protótipos e dos exemplares, seja por oferecer elementos que permitem articular a dimensão da ativação dos estereótipos com a da expressão dos preconceitos, da discriminação e da exclusão social. Em que pese a crescente importância que o conceito ocupa nos estudos sobre a categorização social e a estereotipização, o esclarecimento da dimensão conceitual do essencialismo ainda requer um maior número de estudos para que se alcance um conhecimento mais preciso deste fenômeno. O presente estudo perfila-se nesta busca e indica, numa perspectiva compatível com as investigações desenvolvidas nos últimos anos, que é justificado postular a existência de duas dimensões essenciais do essencialismo, uma naturalista e outra entitativa. Para ser mais exato, o presente estudo reforça as evidências que encontramos em um outro estudo (Pereira, Alvaro \& Schweiger, 2010), ao reafirmar que existe uma diferença, pelo menos enquanto mensurada mediante o paradigma do transplante de cérebros, entre a essencialização das categorias essencialistas naturalizáveis e entitativas.

É importante assinalar, no entanto, que no caso específico da categoria entitativa policial/delinquente, as diferenças entre os países apenas são evidenciadas mediante a análise loglinear nas circunstâncias em que o país é qualificado pela direção do transplante do cérebro e ainda assim, apenas entre os participantes espanhóis.

Ademais, mediante a análise das justificativas apresentadas pelos participantes para as respostas a respeito da estabilidade e da mudança no comportamento que se segue a um presumido transplante de cérebro, fica claro que a dimensão 
da permanência não é decisiva na explicação dos comportamentos ou, pelo menos, não ocupa um papel preponderante nas circunstâncias em que os comportamentos são explicados pelas causas internas, pela história causal ou pela presença de uma intenção deliberada que se manifesta pela presença de motivos e razões para a ação. Este entendimento de que o raciocínio essencialista pode ser colocado em cena tanto para explicar a estabilidade quanto a mudança no comportamento é compatível com uma série de hipóteses desenvolvidas no final dos anos 90 nas quais se postula que os estereótipos podem ser interpretados como gestalts esclarecedoras.

Neste caso, a presença de uma teoria implícita torna possível a expressão do raciocínio categórico essencialista nas circunstâncias em que o agente acolhe uma teoria que lhe permita justificar a estabilidade ou a mudança do comportamento. Os dados aqui arrolados sugerem que estas teorias implícitas podem ser diferenciadas em quatro direções distintas e que as explicações que se centram nas pressões situacionais explicam de forma predominante, mas não exclusivamente, a estabilidade da conduta. Ainda que as outras três teorias explicativas, as causas internas, a história causal e as razões e motivos também possam ser requisitadas para explicar a estabilidade na conduta, as pressões situacionais são arroladas fundamentalmente para explicar a ausência de mudanças nas condutas que se seguem ao presumido transplante de cérebro entre policiais e delinquentes.

Os resultados aqui apresentados suscitam algumas reflexões, apresentadas a título de conclusão do presente artigo. Uma delas se relaciona de forma direta com um limite encontrado na maior parte das teorias sobre os estereótipos. Estas, usualmente se referem a um julgamento acerca dos membros de uma ou mais categorias sociais. O resultado da análise loglinear sugere que podem ser encontradas diferenças no julgamento em função do grau de hegemonia da categoria. Isto indica que a dimensão de análise categoria social parece ser muito ampla e, em certo sentido, não incorpora uma série de elementos que as pessoas adotam durante o julgamento categórico estereotipado.

O que se defende aqui é uma relativização da importância da dimensão categoria social na definição, assim como na formulação das teorias acerca dos estereótipos. Os resultados do programa de investigação ao qual o presente estudo se reporta admoestam sobre a necessidade de definir os estereótipos de uma forma mais abrangente e, para tal, eles podem ser definidos como crenças socialmente compartilhadas a respeito de determinados entes, em geral membros de uma categoria social, que tem por referentes suposições sobre a homogeneidade grupal e sobre os padrões de comportamento comuns adotados pelos membros do grupo, cujos fundamentos são encontrados nas teorias implícitas a respeito dos fatores que determinam os padrões de conduta dos indivíduos.

\section{Referências}

Brewer, M., Hong, Y., \& Li, Q. (2004). Dynamic entitativity: perceiving groups as actors. Em V. Yzerbyt, C. M. Judd \& O. Corneille (Eds.), The psychology of group perception: perceived variability, entitativity and essentialism (pp.25-38). New York: Psychology Press.
Gelman, S. (2004). Psychological essentialism in children. Trends in Cognitive Sciences, 8, 404-409.

Gottfried, G., Gelman, S., \& Schultz, J. (1999). Children's understanding of the brain: from early essentialism to biological theory. Cognitive Development, 14, 147-174.

Haslam, N. (1998). Natural kinds, human kinds, and essentialism. Social Research, 65(2), 1-10.

Haslam, N., Bain, P., Douge, L., Lee, M., \& Bastian, B. (2005). More human than you: attributing humanness to self and others. Journal of Personality an Social Psychology, 89(6), 937-950.

Heider, F. (1970). Psicologia das relações interpessoais. São Paulo: Pioneira (edição original: 1958).

Johnson, C. N. (1990). If you had my brain, where I would be? Children's understanding of the brain and identity. Child Development, 61, 962-972.

Jones, E., \& Davis, K. (1965). From acts to dispositions: the attribution process in perception of person. Em L. Berkowitz (Ed.). Advances in Experimental Social Psychology (vol. 2) (pp. 219-266). New York: Academic Press.

Keller, J. (2005). In genes we trust: the biological component of psychological essentialism and its relationship to mechanisms of motivated social cognition. Journal of Personality and Social Psychology, 88(4), 686-702.

Macrae, C., \& Bodenhausen, G. (2000). Social cognition: thinking categorically about others. Annual Review of Psychology, 51, 93-120.

Mahalingam, R. (2003). Essentialism, culture, and power: representations of social class. Journal of Social Issues, 59(4), 733-749.

Mahalingam, R., \& Rodriguez, R. (2003). Essentialism, power and cultural psychology of gender. Journal of Cognition and Culture, 2, 157-174.

Malle, B. (1999). How people explain behavior: a new theoretical framework. Personality and Psychology Social Review, 3, 23-48.

Malle, B. (2006). How the mind explains behavior. Folk explanations, meaning and Social Interactions. Cambridge, Mass: MIT Press.

Medin, D. (1989). Concepts and conceptual structure. American Psychologist, 44(12), 1469-1481.

Medin, D., Goldstone, R., \& Gentner, D. (1993). Respects for similarity. Psychological Review, 44, 1469-81.

Medin, D., \& Shoben, E. (1988). Context and structure in conceptual combination. Cognitive Psychology, 20, 158-190.

Pereira, M., Alvaro, J.L. \& Schweiger, I (2010). Essentialism and the expression of social stereotypes: a comparative study in Spain, Brazil and England. Spanish Journal of Psychology, 13 (2), 808-817

Picket, C. (2001). The effects of entitativity beliefs on implicit comparisons between group members. Personality and Social Psychology Bulletin, 27(5), 515-525.

Rosch, E. (1975). Cognitive representations of semantic categories. Journal of Experimental Psychology: General, 104, 192-233.

Rosch, E., Mervis, C., Gray, W., Johnson, D., \& Boyes-Braem, P. (1976). Basic objects in natural categories. Cognitive Psychology, 8, 383-439.

Rothbart, M., \& Taylor, M. (1992). Category labels and social reality: do we view social categories as natural kinds? Em G. Semin \& K. Fiedler (Eds.). Language, interaction and social cognition (pp.11-36). London: Sage. 
Sherman, J. (1996). Development and mental representations of stereotypes. Journal of Personality and Social Psychology, 70, 1126-1141

Yzerbyt, V., Rocher, S., \& Schadron, G. (1997). Stereotypes as explanations: a subjective essentialistic view of group perception. Em R. Spears, P. Oakes, N. Ellemers \& A. Haslam (Eds.). The Psychology of stereotyping and group life. (pp.2050). London: Basil Blackwell.

Recebido em 03.02.09

Primeira decisão editorial em 08.02.10

Versão final em 05.04.10 Aceito em 03.05.10 